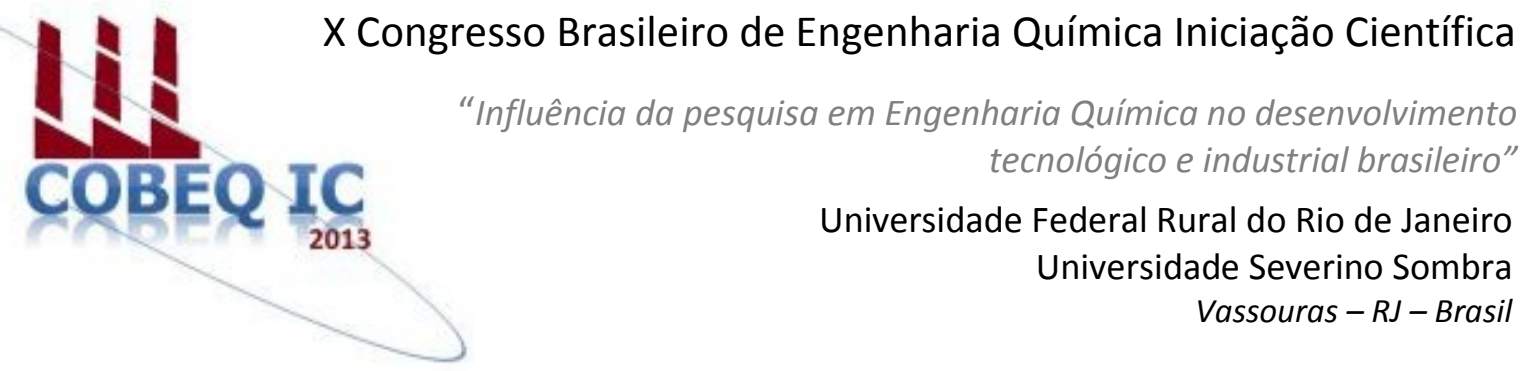

\title{
SECAGEM DA AMORA-PRETA (Rubus spp.) VISANDO MINIMIZAR AS PERDAS NO CONTEÚDO DE ANTOCIANINAS
}

\author{
MACHADO*1 ${ }^{1}$, F. R.; OLIVEIRA ${ }^{2}$, E. G.; ROSA ${ }^{3}$, G. S. \\ ${ }^{1}$ Aluna de EQ/UNIPAMPA ${ }^{2}$ Professora da EA/UNIPAMPA ${ }^{3}$ Professora da EQ/UNIPAMPA \\ Universidade Federal do Pampa - Engenharia Química - UNIPAMPA, \\ Endereço - Travessa 45, $n^{\circ} 1650$ - Bagé, CEP 96413-170, RS, \\ e-mail: gabrielarosa@unipampa.edu.br
}

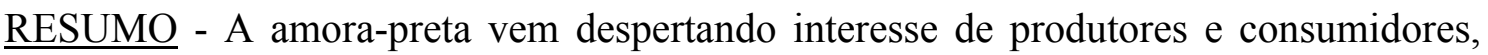
principalmente pelo consumo associado às suas propriedades benéficas à saúde, as quais estão ligadas à alta concentração de antocianinas, que são responsáveis pela coloração roxa e tonalidades de vermelho, encontradas tanto em flores como em frutos. Uma boa alternativa para preservar as propriedades do produto in natura é a secagem, que visa reduzir o conteúdo de umidade no material, reduzindo a proliferação de microorganismos. Este trabalho teve como objetivo determinar a faixa de trabalho para a operação de secagem da amora-preta, de forma a minimizar a perda do conteúdo de antocianinas. Foram realizados experimentos de secagem utilizando o secador em leito fixo com fluxo paralelo de ar. Para determinação das antocianinas totais presentes nas amostras in natura e secas foi utilizado o método espectrofotométrico de $\mathrm{pH}$ Único, sendo a extração realizada com solução etanol-água (70:30). Para a perda de compostos antociânicos, verificou-se que não houve uma correlação entre a maior degradação e a temperatura do ar de secagem, conforme reportado na literatura.
\end{abstract}

Palavras chave: amoreira-preta, leito fixo, compostos antociânicos.

\section{INTRODUÇÃO}

A amoreira-preta é um arbusto de porte ereto, semi-ereto ou rasteiro, que faz parte de um grupo de plantas do gênero Rubus, este gênero pertence à família Rosacea (Poling, 1996). Cada fruto agregado possui cerca de 4 a $7 \mathrm{~g}$, apresentando coloração negra e sabor ácido a doce-ácido (Fachinello et al., 1994). Os frutos da amoreira-preta (Rubus spp.) são de grande qualidade nutricional, além de suas características atrativas de cor e sabor.

A amora-preta apresenta alta atividade antioxidante, além de ser rica em antocianinas (pertencente ao grupo dos flavonoides), que atribuem a coloração vermelho púrpura, roxa e azul presente em frutas e vegetais. As antocianinas apresentam propriedades que associam seu consumo a hábitos saudáveis de alimentação e contribuição medicinal para a saúde humana. As antocianinas fazem parte da área mais ativa da pesquisa de flavonoides (Harbone e Willians; 2000). Estes compostos podem ser encontrados na uva, cereja, morango, amora, entre outras (Malacrida e Motta, 2006).

Várias tecnologias têm sido empregadas para preservar as frutas, uma das mais 
importantes é a operação de secagem. Esse processo é o método mais antigo de preservação de alimentos, sendo realizado com o objetivo de remover a umidade, impedindo o crescimento e a reprodução de microorganismos que proliferam na presença de umidade. Esta operação unitária pode apresentar períodos de taxa constante e decrescente de migração de umidade (Mujumdar, 2006). A cinética de secagem pode ser controlada pelas características da matriz do material e pelas variáveis, como temperatura, velocidade e umidade relativa do ar.

A secagem pode causar modificação e deterioração sobre compostos bioativos do alimento. Quando este processo não é corretamente aplicado, pode haver degradação significativa de substâncias benéficas para a saúde, como é o caso das antocianinas. Estas apresentam potencial para substituição dos corantes artificiais vermelhos; porém, são instáveis frente ao processamento de alimentos, sendo a temperatura um dos principais fatores envolvidos na degradação destes pigmentos (Zen, 2010).

Este trabalho teve como objetivo determinar a faixa de trabalho para a operação de secagem da amora-preta, de forma a minimizar a perda o conteúdo de antocianinas.

\section{MATERIAL E MÉTODOS}

\section{Matéria prima}

A matéria prima utilizada foi a amorapreta cultivar Tupy, proveniente da cidade de Bagé/RS. A análise de umidade da matéria prima foi determinada pelo método gravimétrico de secagem em estufa a $105^{\circ} \mathrm{C}$ por $24 \mathrm{~h}$ (AOAC, 1995).

\section{Procedimento Expeimental}

Para o estudo da secagem da amorapreta utilizou-se um secador de leito fixo de fluxo paralelo, conforme mostra Figura 1.

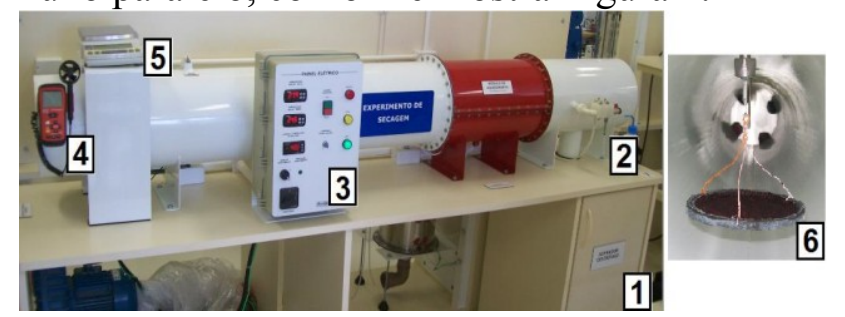

Figura 1 - Secador de leito fixo.
O equipamento utilizado foi um secador composto por soprador centrífugo (1) de fluxo paralelo, psicrômetro (2), painel elétrico (3) que indicava a temperatura do ar de secagem e as temperaturas de bulbo seco e de bulbo úmido do ar (entrada do ar de secagem). Para verificar a velocidade do ar fez-se o uso do anemômetro (4). A determinação das massas das amostras foi realizada por meio de balança eletrônica (5) com precisão de 0,01 g, acoplada diretamente à bandeja (6) no interior do secador. A bandeja (6) utilizada possuía forma circular com diâmetro de $9,5 \mathrm{~cm}$ e altura de $0,5 \mathrm{~cm}$. Para a realização dos experimentos de secagem, as frutas foram trituradas em moinho de hélice. Durante os experimentos todos os parâmetros do equipamento foram monitorados, finalizando os experimentos quando a amostra atingiu peso constante (sendo este conteúdo de umidade considerado como de equilíbrio). Os experimentos foram realizados nas temperaturas de 40,50 e $60{ }^{\circ} \mathrm{C}$, com velocidades do ar de secagem de 1,0 1,5 e 2,0 $\mathrm{m} / \mathrm{s}$.

Para determinação das antocianinas totais presentes nas amostras in natura e secas, foi utilizado o método espectrofotométrico de pH único (Fuleki e Francis, 1968). A extração foi realizada pela solução etanol-água (70:30) e $\mathrm{HCl}$ para ajustar o $\mathrm{pH}$ do meio para 2,0. As amostras para a extração foram deixadas em repouso, ao abrigo da luz, por $24 \mathrm{~h}$ a $5^{\circ} \mathrm{C}$. Ao término desse tempo, as amostras foram filtradas e transferidas para balão volumétrico de $100 \mathrm{~mL}$, tendo seu volume completado com a solução etanol-água. Após, realizou-se uma diluição do extrato concentrado com solução etanol-HCl $1,5 \mathrm{~N}$ (85:15). Os valores de absorbâncias foram lidos em espectrofotômetro UV/VIS, em comprimento de onda de $535 \mathrm{~nm}$. Para o cálculo do conteúdo de antocianinas totais utilizou-se a Equação 1.

$$
A n t_{\text {Total }}=\frac{D O_{535} \cdot V_{E C} \cdot V_{E d} \cdot 1000}{V_{A l q} \cdot m \cdot E_{1}^{1 \%} \%}
$$

Na Figura 2 é mostrado o procedimento para extração das antocianinas. 


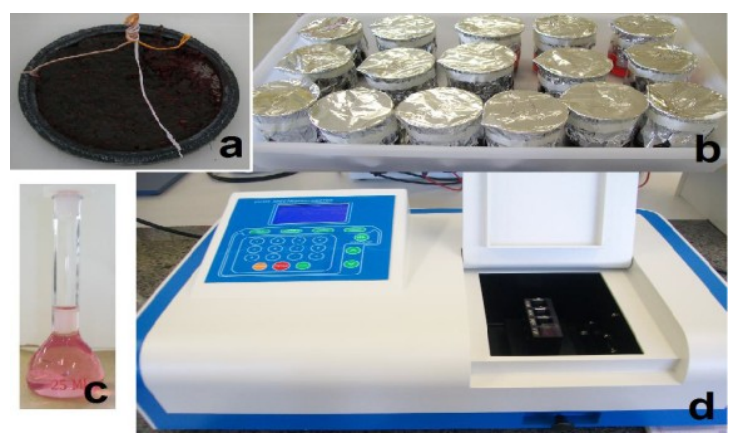

Figura 2 - Determinação das antocianinas: (a) amostra seca (b) solução com as amostras (c) solução diluída (d) espectrofotômetro UV/VIS.

\section{RESULTADOS E DISCUSSÃO}

As amostras da amora-preta in natura caracterizaram-se por apresentar um elevado conteúdo de umidade inicial $(85,40 \pm 0,014 \%$ (b.u.)). A umidade de equilíbrio das amostras foi determinada pelas isotermas de equilíbrio através do método gravimétrico estático, com soluções de ácido sulfúrico, nas temperaturas de 40,50 e $60{ }^{\circ} \mathrm{C}$.

$\mathrm{Na}$ Figura 3 são representadas as curvas de cinética de secagem para amora-preta nas temperaturas de 40 e $60{ }^{\circ} \mathrm{C}$ e velocidades do ar de secagem de 1 e $2 \mathrm{~m} / \mathrm{s}$

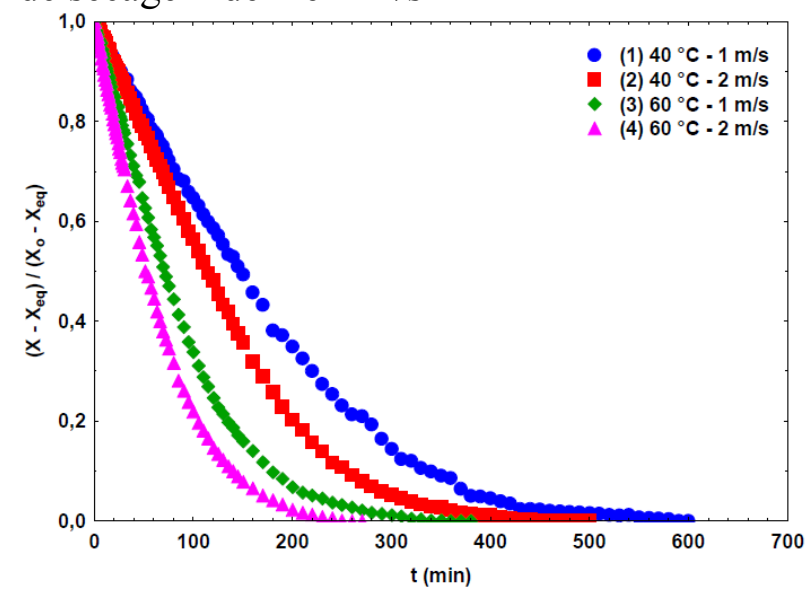

Figura 3 - Cinética de secagem nas temperaturas de 40 e $60{ }^{\circ} \mathrm{C}$ e velocidades do ar de secagem de 1 e $2 \mathrm{~m} / \mathrm{s}$.

Analisando a Figura 3, observa-se que a cinética de secagem foi influenciada tanto pela temperatura como pela velocidade do ar de secagem, uma vez que na temperatura e velocidade mais baixa $\left(40{ }^{\circ} \mathrm{C} ; 1 \mathrm{~m} / \mathrm{s}\right)$ a secagem ocorreu em um período de tempo de $10 \mathrm{~h}$ (600 min), enquanto que para a temperatura e velocidade mais alta $\left(60{ }^{\circ} \mathrm{C} ; 2\right.$ $\mathrm{m} / \mathrm{s})$ a secagem teve duração de 4,5 h (270 min). De acordo com Zen (2010), durante a operação de secagem a diferença de temperatura entre o material e o ambiente, e serão as forças motrizes do processo, essa será a transferência de calor. Do ponto de vista da transferência de massa, a força motriz para remoção de água do material é a diferença de teores de umidade do material e o equilíbrio.

$\mathrm{Na}$ Figura 4 são mostradas diferentes curvas de secagem para a amora-preta na temperatura de $50{ }^{\circ} \mathrm{C}$ e velocidade do ar de secagem a $1,5 \mathrm{~m} / \mathrm{s}$.

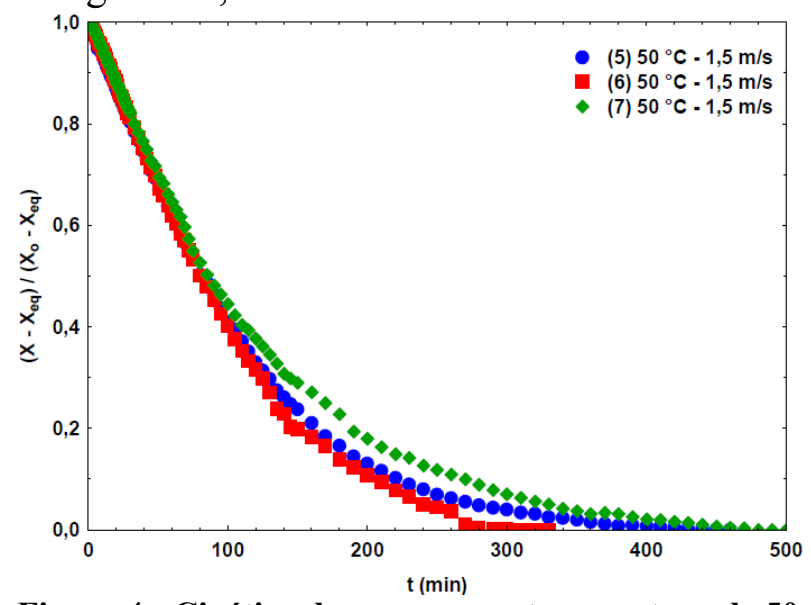

Figura 4 - Cinética de secagem na temperatura de 50 ${ }^{\circ} \mathrm{C}$ e velocidade do ar de secagem $1,5 \mathrm{~m} / \mathrm{s}$.

Pode-se observar que as curvas da Figura 4 apresentaram o mesmo comportamento da Figura 3, nota-se que em todos os experimentos de secagem aconteceu a remoção de umidade mais expressiva nos tempos iniciais dos ensaios (taxa constante).

Nas Figuras 5 e 6 são representadas as curvas de taxa de secagem em função da umidade (b.s.) do material.

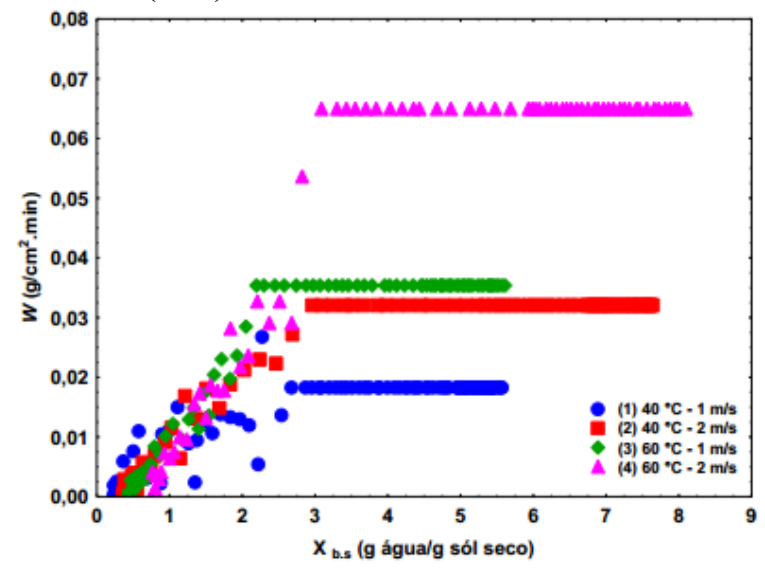

Figura 5 - Curva da taxa de secagem nas temperaturas 40 e $60^{\circ} \mathrm{C}$ e velocidades do ar de secagem de 1 e 2 m/s. 


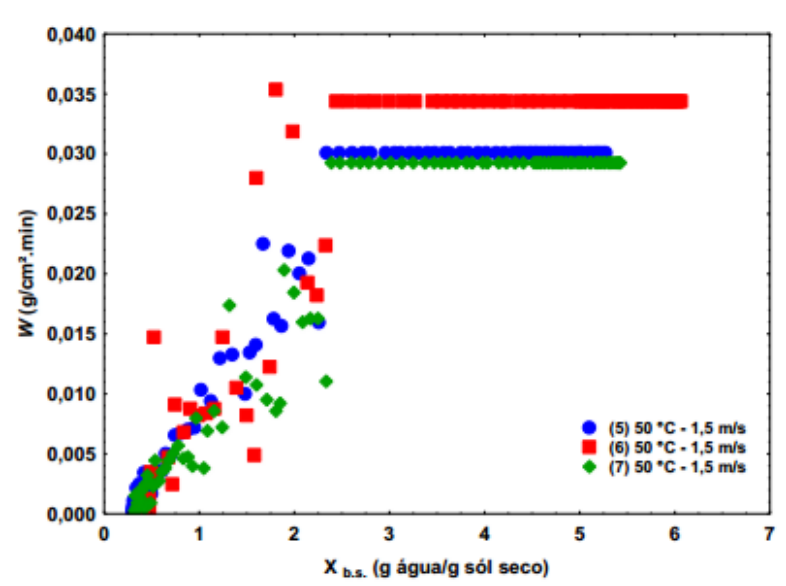

Figura 6 - Curva da taxa de secagem na temperatura de $50{ }^{\circ} \mathrm{C}$ e velocidade de secagem $1,5 \mathrm{~m} / \mathrm{s}$.

Observa-se para ambas as temperaturas de secagem, que o processo ocorreu em período distintos inicialmente taxa constante e após taxa decrescente. Para o período em que a secagem ocorreu em taxa constante, o material apresenta uma fina camada de umidade na sua superfície, essa umidade pode ficar muito menor do que aquela das camadas mais internas, pois o ar de secagem remove a umidade desta região mais rapidamente do que o interior do sólido pode repor (PACHECO, 2010). Com a ausência de umidade na superfície, acontece o período de taxa decrescente e assim a resistência interna passa a predominar e a taxa de secagem diminui, pois a transferência de massa passa a ser governada pelo mecanismo de difusão. Segundo Foust et al. (1982), quando o material apresenta estrutura fibrosa, como nos alimentos, a remoção de umidade será mais lenta devido ao movimento do líquido ocorrer por difusão, dessa forma retém a umidade na taxa decrescente do interior dos poros delgados.

Este estudo foi realizado para determinar quais as condições ideais para o processo de secagem, a fim de minimizar a perda do conteúdo das antocianinas totais da amorapreta. Na Tabela 1 são apresentados os resultados do conteúdo de antocianinas totais, obtidas nas amostras.

Tabela 1 - Determinação das antocianinas totais da amostra.

\begin{tabular}{|c|c|c|c|c|c|c|c|}
\hline $\begin{array}{c}\mathrm{N}^{\mathrm{o}} \text { do } \\
\text { experimento }\end{array}$ & $\begin{array}{l}T_{a r} \\
\left({ }^{\circ} \mathrm{C}\right)\end{array}$ & $\begin{array}{c}v_{a r} \\
(\mathrm{~m} / \mathrm{s})\end{array}$ & $\begin{array}{c}t \\
(\min )\end{array}$ & $\begin{array}{c}A n t_{\text {Total }} \text { (b.u.)* } \\
\text { (mg/100 g de } \\
\text { amostra) }\end{array}$ & $\begin{array}{c}A n t_{\text {Total }}(\text { b.s. })^{*} \\
(\mathrm{mg} / 100 \mathrm{~g} \text { de sólido } \\
\text { seco) }\end{array}$ & $\begin{array}{l}\text { Percentual } \\
\text { Mantido } \\
A n t_{\text {Total }}(\%)\end{array}$ & $\begin{array}{c}\text { Redução } \\
A n t_{\text {Total }} \\
(\%)\end{array}$ \\
\hline 1 & 40 & 1 & 600 & $305,92 \pm 33,52$ & $398,86 \pm 43,70$ & 39,9 & 60,12 \\
\hline 2 & 40 & 2 & 500 & $182,87 \pm 6,36$ & $244,81 \pm 8,52$ & 24,5 & 75,52 \\
\hline 3 & 60 & 1 & 380 & $294,10 \pm 2,91$ & $355,62 \pm 3,52$ & 35,6 & 64,44 \\
\hline 4 & 60 & 2 & 270 & $194,26 \pm 13,73$ & $246,22 \pm 17,39$ & 24,6 & 75,38 \\
\hline 5 & 50 & 1,5 & 460 & $177,36 \pm 15,27$ & $221,42 \pm 19,07$ & 22,1 & 77,86 \\
\hline 6 & 50 & 1,5 & 330 & $220,21 \pm 10,61$ & $279,46 \pm 13,46$ & 27,9 & 72,06 \\
\hline 7 & 50 & 1,5 & 500 & $353,89 \pm 16,11$ & $438,52 \pm 19,96$ & 43,8 & 56,15 \\
\hline in natura & & & & $163,02 \pm 0,12$ & $1000,12 \pm 0,72$ & - & - \\
\hline
\end{tabular}

*Média \pm desvio médio $(\mathrm{n}=2)$.

Com base nos resultados apresentados na Tabela 1, pode-se observar que o conteúdo de antocianinas totais da amora-preta (Rubus spp.) in natura está de acordo com valores reportados na literatura. Araújo (2009) encontrou 186,44 mg/100 g (b.u.) para polpa de amora-preta (Rubus spp.). Mota (2006) obteve $116,46 \mathrm{mg} / 100 \mathrm{~g}$ (b.u.) de antocianinas totais para a polpa de amora-preta. Também observa-se que a menor redução (perda) no conteúdo de antocianinas foi observado para o experimento 7 , o que pode estar relacionado 
com um problema de amostragem, pois este experimento diferencia-se de todos os demais. No experimento 5 foi verificado a maior redução (perda) de antocianinas que envolveu as mesmas condições do ponto central. De acordo com a literatura, era esperada que a redução do conteúdo de antocianinas apresentasse forte correlação com a maior temperatura $\left(60{ }^{\circ} \mathrm{C}\right)$, o que não aconteceu neste estudo. De acordo com Stringheta (1991 apud Lopes et al., 2007) a temperatura é um fator importante na estabilidade das antocianinas, pois quando a amostra é submetida a uma temperatura superior a ambiente $\left(25^{\circ} \mathrm{C}\right)$, a sua degradação será maior.

Sobre os resultados apontados no presente estudo, pode-se fazer algumas considerações, como o processamento durante o preparo das amostras, tanto durante a trituração quanto maceração, como também a amostragem, ter influenciado no conteúdo de antocianinas, acarretando algumas diferenças encontradas. Segundo Francis (1982 apud Oliveira, 2011), na maioria das frutas e vegetais, os pigmentos se encontram localizados em células próximas à superfície. Outra justificativa dessa expressiva redução no conteúdo de antocianinas pode ser explicada pelo fato das antocianinas serem pigmentos bastante instáveis ao processamento e armazenamento, alterando a sua cor. Além disso, a exposição das amostras durante os longos tempos em que as secagens ocorreram podem ter provocado a degradação das antocianinas.

\section{CONCLUSÃO}

As amostras da amora-preta in natura apresentaram um elevado conteúdo de umidade inicial $(85,40 \pm 0,014 \%$ (b.u.)). A secagem da amora-preta apresentou dois períodos distintos, inicialmente taxa constante e após, taxa decrescente.

O conteúdo de antocianinas totais da amora-preta (Rubus spp.) in natura apresentou valor semelhante com valores reportados na literatura. Verificou-se que as perdas do conteúdo de antocianinas após a secagem variaram entre 56 e $77 \%$. Algumas considerações como o preparo da amostra, exposição das amostras durante longos tempos de secagem, além da temperatura do ar de secagem, podem ter influenciado no conteúdo das antocianinas, acarretando as diferenças encontradas. Neste sentido, torna-se justificável o estudo do processo de secagem da amora-preta visando minimizar a perda de compostos bioativos (antocianinas) e ao mesmo tempo, prolongar a vida útil da amorapreta a fim de viabilizar o seu uso para a fabricação de corantes naturais, substituindo os corantes sintéticos.

\section{NOMENCLATURA}

\begin{tabular}{|c|c|}
\hline Ant $_{\text {Total }}$ & Antocianinas totais \\
\hline$D O_{535}$ & $\begin{array}{l}\text { Absorbância do extrato } \\
\text { diluído }\end{array}$ \\
\hline$E^{1 \%}{ }_{1 \mathrm{~cm}}$ & $\begin{array}{l}\text { Coeficiente de extinção } \\
\text { médio }\end{array}$ \\
\hline$m$ & Massa da amostra \\
\hline$t$ & Tempo de secagem \\
\hline$T_{a r}$ & Temperatura do ar \\
\hline$v_{a r}$ & $\begin{array}{l}\text { Velocidade do ar de } \\
\text { secagem }\end{array}$ \\
\hline$V_{A l q}$ & Volume da alíquota \\
\hline$V_{e c}$ & $\begin{array}{l}\text { Volume total do extrato } \\
\text { concentrado }\end{array}$ \\
\hline$V_{e d}$ & $\begin{array}{l}\text { Volume total do extrato } \\
\text { diluído }\end{array}$ \\
\hline$W$ & Taxa de secagem \\
\hline
\end{tabular}

\section{REFERÊNCIA}

ARAÚJO, P. F. de. (2009), Atividade antioxidante de néctar de amora-preta (Rubus spp.) e sua influência sobre os lipídios séricos, glicose sanguínea e peroxidação lipídica em hamsters (Mesocricetusauratus)

hipercolesterolêmicos. Universidade Federal de Pelotas. Pelotas - RS.

AOAC (1995) - Association of Official Analytical Chemists. Official Methods of Analysis. 14 ed. v.1.

FACCHINELLO, J. C.; HOFFMANN, A.; SANTOS, A. M. (1994), "Amoreira-preta, framboesa e mirtilo: pequenos frutos para o sul do Brasil". CONGRESSO BRASILEIRO DE FRUTICULTURA, 13, Salvador $-\mathrm{BH}$.

FRANCIS, F. J. (1982), "Analysis of anthocyanins in foods". In.: MARKAKIS, 
P., Anthocyanins as food colors. New York: Academic Press, p. 181-207. Apud OLIVEIRA, I. R. N. (2011), Antocianinas extraídas de capim-gordura (Melinis minutiflora): Atividade antioxidante, microencapsulamento por atomização e estabilidade. Universidade Federal de Viçosa. Viçosa-MG.

FOUST, A. S.; WENZEL, L. A.; CLUMP, C. W.; MAUS, L.; ANDERSEN, L. B.( 1982), Princípios das Operações Unitárias. Rio de Janeiro: LTC.

FULEKI T. e FRANCIS F. J. (1968), Quantitative methods for anthocyanins: 1. Extraction and determination of total anthocyanin in cranberries. Journal of Food Science, v.33, p. 72-77.

HARBORNE, J. B.; WILLIANS, C.A.(2000), Advances in flavonoid research since 1992. Phytochemistry, v. 55, p. 481-504.

MALACRIDA, C. R.; MOTTA, S. da. (2006), Antocianinas em suco de uva: composição e Estabilidade. B.CEPPA, Curitiba, v. 24, n.1, p. 59-82.

MOTA, R. V. de. (2006), Caracterização física e química de geleia de amora-preta. Ciência e Tecnologia de Alimentos, v.26, n.3, p. 539-543. Campinas - SP.

MUJUMDAR, A. S. et al. (2006), Handbook of industrial drying. 3 ed.

PACHECO, C.R.F (2010), Conceitos básicos de Secagem. Curso de Especialização de Papel e Celulose.

POLING, E.B. (1996), "Blackberries". Journal of Small Fruit and Viticulture, Binghamton, v.14, n.2, p. 38-69.

STRINGHETA, P.C.; (1991), Identificação da estrutura e estudo da estabilidade das antocianinas extraídas da inflorescência de capim gordura (Mellinis minutuflora, Pal de Beauv.). Universidade Estadual de Campinas. Campinas - SP. Apud LOPES, T. J.; Xavier, M. F.; QUADRI, M. G. N.; QUADRI, M. B. (2007), "Antocianinas: Uma breve revisão das características estruturais e da estabilidade". Revista Brasileira de Agrociência, v.13, n.3, p. 291-297.

ZEN, F. G. (2010), Estudo da secagem convectiva do bagaço de mirtilo visando minimizar a perda de compostos antociânicos. Trabalho de conclusão do curso de Engenharia Química. Universidade Federal do Rio Grande do Sul - UFRGS. 